\title{
Epilepsy with onset at over 50 years of age: clinical and electroencephalographic characteristics
}

\author{
Epilepsia com início após os 50 anos de idade: características clínicas e eletrencefalográficas \\ Glória Maria Almeida Souza Tedrus¹, Lineu Corrêa Fonseca¹, Elizardo Nogueira Junior², Daniele Pazetto³
}

\begin{abstract}
Epilepsy in older individuals has an elevated incidence. The objective of the present work was to evaluate the clinical, EEG and brain imaging aspects in patients showing late-onset epilepsy. Fifty-five patients with late-onset epilepsy (older than 50 years) were evaluated. They were composed of two groups according to the onset age of the epilepsy seizure (ES): 51-60 (G51-60) and over 60 (G60+) years. Focal ES predominated although they were less frequent in G60+. The occurrence of status epilepticus was high and more frequent in G60+ whereas seizures in series predominated in G51-60. Symptomatic epilepsy was more frequent and the vascular etiology predominated. Epileptiform activity was associated with a greater number of ES, and background activity abnormalities were more frequent in G60+. In conclusion, epilepsy with onset at over 50 was predominantly focal and symptomatic, with a high occurrence of status epilepticus and of seizures in series.
\end{abstract}

Key words: epilepsy, aged, epileptic seizures, electroencephalography.

\section{RESUMO}

Epilepsia no idoso tem elevada incidência e peculiaridades pouco estudadas. 0 objetivo do presente trabalho foi avaliar aspectos clínicos e eletrencefalográficos de pacientes que apresentaram a primeira crise epiléptica (CE) tardiamente. Foram avaliados 55 pacientes com epilepsia tardia (com início após os 50 anos), divididos em dois grupos segundo a idade de início das CE: de 51-60 anos (G51-60) e após os 60 anos (G60+). Predominaram as CE focais, que foram menos frequentes em G60+. A ocorrência de status epilepticus foi elevada e mais frequente em G60+, enquanto as CE em série predominaram em G51-60. A epilepsia sintomática foi a mais frequente e de etiologia vascular. Atividade epileptiforme esteve associada ao maior número de crises epilépticas. Anormalidades da atividade de base ao EEG foram mais frequentes em G60+. Em conclusão, a epilepsia iniciada após os 50 anos é predominantemente focal e sintomática, com alta ocorrência de status epilepticus e CE em série.

Palavras-Chave: epilepsia, idoso, crises epilépticas, eletroencefalografia.

The elevated incidence of epilepsy with onsetat over 50 years of age, in relation to the total number of new cases of epilepsy, has been ignored in the literature in recent decades ${ }^{1}$.

Studies have shown that epilepsy affects approximately 1 to $2 \%$ of the elderly population, and the incidence increases progressively with the advance in age. These cases of epilepsy can occur due to an acute cerebral seizure or have no apparent precipitator ${ }^{2,3}$.

On the other hand, there is consensus in the literature that epileptic seizures (ES) are more difficult to diagnose in the elderly for various reasons such as the difficulty in obtaining an accurate clinical history, a frequently atypical ictal presentation, difficulty in making a differential diagnosis between an epileptic and non-epileptic event ${ }^{3-6}$ and due the occurrence of comorbidities ${ }^{5,6}$.

Although epilepsy is considered to be one of the commonest neurological affections in the elderly, and despite the need to take public health measures due to the progressive increase in the elderly population, particularly in developing countries, no national (Brazilian) publications and only a few international ones on epilepsy in this age range were found.

Thus, the objective of the present study was to evaluate the clinical and electroencephalographic aspects of ES and epilepsies in patients with late-onset ES at over 50 years of age, also considering different age ranges.

\section{METHODS}

\section{Patients}

Fifty-five patients, consecutively attended at the neurological clinic of the Celso Pierro Hospital and Maternity

\footnotetext{
'Department of Neurology, Faculdade de Medicina, Pontifícia Universidade Católica de Campinas (PUC-Campinas), Campinas SP, Brazil;

2Department of Neurology, Hospital e Maternidade Celso Pierro, PUC-Campinas, Campinas SP, Brazil;

${ }^{3}$ Scholarship student Reitoria, PUC-Campinas, Campinas SP, Brazil.

Correspondence: Lineu Corrêa Fonseca; Rua Sebastião de Souza 205 / sala 122; 13013-173 Campinas SP - Brasil; E-mail: lineu.fonseca@uol.com.br

Conflicts of interest: There is no conflict of interest to declare.

Received 04 April 2012; Received in final form 25 June 2012; Accepted 02 July 2012.
} 
of Pontifícia Universidade Católica de Canpinas (PUCCampinas) between February 2010 and March 2011,had epilepsy with onset at over 50 years of age, were included in this prospective study. The patients were classified into two groups according to the ES onset age: from 51 to 60 (G51-60) and over 60 (G60+). The study was approved by the Ethics Committee for research in human beings of PUC-Campinas and the patients signed a consent form.

\section{Procedures}

The following procedures were carried out:

A clinical-neurological assessment evaluate socio-demographic and clinical aspects: age, gender, marital status, onset age, type and frequency of ES, evolution time of the epilepsy, use of anti-epileptic drugs (AED), antecedents of clinical and neurological diseases, clinical-neurological examination.

Digital electroencephalogram was obtained at rest, during hyperpnea and with intermittent photo-stimulation, preferably on the day following an ES. The presence of alterations in the background activity, of non-specific abnormalities and of epileptiform activity (EA), characterized according to its location, extent and type, that is, spikes, complexes of slow-wave spikes or sharp spikes, was studied.

Brain imaging data were obtained for all the patients, using MRI for 35 cases and the CT-scan for 20 cases.

\section{Data analysis}

The ES and epilepsies were classified according to the criteria of the International Classification of Epilepsies and Epileptic Syndromes?

To characterize the presentation of the ES, the following definitions proposed by Massengo et al. ${ }^{6}$ were used in this study: status epilepticus (SE) - a more prolonged ES or a sequence of ES without complete recovery of consciousness between them - and ES in series - various ES in one day.

Controlled epilepsy was considered as that in which there had been no ES during the previous 12 months. About therapy with AED, the patients were classified as in a monotherapeutic regime or a polytherapeutic one (two or more AED).

Fisher's exact or $\chi^{2}$ tests were used to compare the proportions between the groups for the categorical variables, and the level of significance was $\mathrm{p}<0.05$.

\section{RESULTS}

Fifty-five patients (27 male cases) with a mean age of $67 \pm 8.0$ were studied, of which 30 showed the ES onset between 51 and 60 years of age, and 25over 60 .

Thirty-two (58\%) patients were married, 7 (12.7\%) single and 16 (29\%) either divorced or widowed.

\section{Epileptic seizures}

The mean onset age for the ES was 61 (51 to 83) and Table 1 shows the clinical data of the patients according to their onset age range (G51-60 and G60+ groups).

Focal ES occurred in 37 (67.3\%) cases as follows: complex in $21(38.2 \%)$ cases, motor/sensitive in 12, autonomic in 3, and psychic in 1 case. Generalized tonic-clonic (TCG) ES only occurred in 18 (32.7\%) cases.

The proportion of patients with focal seizures, especially complex focal seizures, was lower in G60+ than in G51-60 $\left(\chi^{2}, \mathrm{p}<0.05\right)$.

The first ES was characterized by status epilepticus in 13 patients (23.6\%) and ES in series in 5 cases (9.1\%). During the period studied, 8 (14.5\%) of the patients suffered another status epilepticus or ES in series episode.

As shown in Table 1, when comparing the groups classified according to onset age, a greater occurrence of status epilepticus was found in the G60+ group, and of ES in series in the G51-60 group (Fisher's exact test, $\mathrm{p}<0.05$ ).

The postictal period was prolonged in 7 (12.7\%) patients.

\section{Electroencephalogram}

Focal ES was registered in two patients.

On the interictal EEG, the background activity was normal in $23(41.8 \%)$ cases, abnormal due to the presence of slow continuous activity in 19 (34.5\%) cases and intermittent in 13 $(23.6 \%)$ cases (Table 1$)$.

The recording of continuous abnormality in the background activity was more common in patients with an onset age of over 60 than in the G51-60 group $\left(\chi^{2}, \mathrm{p}<0.05\right)$.

EA, characterized by spikes, sharp waves or complexes of spikes and sharp wave - slow waves was recorded in 38 (69.1\%) cases.

\section{Epileptic syndromes}

According to the ILAE criteria, focal symptomatic epilepsy was characterized in $37(67,3 \%)$ cases, probably symptomatic in 17 (30,9\%), and generalized idiopathic in 1 case (Table 1 ).

No significant difference was observed between G51-60 and G60+ groups with respect to the proportions of the different epileptic syndromes.

\section{Generalized idiopathic epilepsy}

One 51-year old patient suffered his first ES, of the GTC type, while awake. The neurological examination and TC were normal, and the EEG showed normal background activity and generalized spike wave, bilateral and synchronous discharges. The generalized idiopathic epilepsy (GIE) was diagnosed, and he suffered a second ES six months after the first episode, when treatment with AED was started. There was no previous history of ES or of the use of drugs with high potential epileptogenic properties. 


\section{Symptomatic epilepsy}

Symptomatic epilepsy was diagnosed in 37 (67.2\%) of the cases, since the alterations in the imaging exams suggested a cause/effect relationship compatible with the localization of an ictal manifestation and other clinical aspects. Stroke was the most frequent etiology, corresponding to 28 (50.1\%) of the cases (Table 1).

Vascular alterations were observed in the imaging exams and a history of an ischemic stroke in $21(38.1 \%)$ of the cases. In three cases, ES occurred together with the installing of ischemic strokes, and in two SE with the subsequent recurrence of the ES during the period of the study.

An association was found between the occurrence of strokes and the register of abnormality in the background activity by slow continuous or intermittent activity $\left(\chi^{2}, p<0.05\right)$.

The presence of vascular diseases characterized by old ischemic areas was observed in the neuroimaging exams in 7 $(12.7 \%)$ cases, without any history of prior clinical manifestation, but suggesting a causal relationship with the ES.

The etiological diagnosis was sequel of traumatic brain injury in four of the cases, neurocysticercosis of the vesicular type in two cases, and arteriovenous malformation, neurofibromatosis and degenerative vascular disease in one case each.

One of the patients with symptomatic epilepsy showed two types of ES, suggesting different epileptic syndromes of which one was post-stroke symptomatic epilepsy and the other possibly temporal lobe epilepsy. Initially this patient had two episodes of GTC-type ES in sequence to the installation of an ischemic stroke, with a hemiparesis, aphasia and right homonymous hemianopsia. The CT-scan showed a left parietal-occipital ischemic area, and in the following 24 months the patient had one more GTC. However, 16 months after the stroke, the patient started having short episodes of "feeling bad" with "dizziness that was difficult to describe", during which he would make non-comprehensible sounds, following which his responsiveness was undermined. These episodes occurred with an irregular frequency, sometimes several in the same day. On carrying out an investigation using the MRI, an area of left occipital gliosis, areas of subcortical microangiopathy, a volumetric reduction in $\mathrm{T} 1$ and an increase in the T2 signal of the left hippocampus, were observed.

Other brain imaging findings were observed in six other patients with symptomatic epilepsy, not correlated with the localization of the EA or ES, that is, intracranial calcifications suggestive of neurocysticercosis in five patients, and in one case, basal ganglia calcifications calcifications, compatible with Fahr's disease.

\section{Probably symptomatic focal epilepsies}

A diagnosis of focal, probably symptomatic epilepsy was made in 17 (30.9\%) of the cases. Focal ES occurred in 14 of these patients and status epilepticus in 2 cases.

In nine cases, the following alterations in the brain imaging exam could not be correlated with the ES: diffuse cortical atrophy in five cases, and focal atrophy or intracranial calcifications in two cases each. In eight patients, the brain imaging exams were normal.

Alterations in background activity were observed on the EEG in four cases, and an ES was recorded in one case.

Table 1. Clinical data of 55 patients with epilepsy, according to the epileptic seizures onset age.

\begin{tabular}{|c|c|c|c|c|}
\hline \multirow[b]{2}{*}{ Clinical data } & \multicolumn{3}{|c|}{ Epileptic seizures onset age range } & \multirow[b]{2}{*}{$p$-value* } \\
\hline & $\begin{array}{l}\text { Whole group } \\
n=55(100 \%)\end{array}$ & $\begin{array}{c}51 \text { to } 60 \\
n=30(54.5 \%)\end{array}$ & $\begin{array}{c}\text { Over } 60 \\
n=25(45.5 \%)\end{array}$ & \\
\hline Focal epileptic seizure & $37(67.3)$ & $24(80.0)$ & $13(52.0)$ & $0.028 * *$ \\
\hline Complex & $21(38.2)$ & $16(53.3)$ & $5(20.0)$ & \\
\hline Others & $16(29.1)$ & $8(26.7)$ & $8(32.0)$ & $0.025^{* *}$ \\
\hline Generalized tonic-clonic seizure & $18(32.7)$ & $6(20.0)$ & $12(48.0)$ & \\
\hline Epileptic seizures in series & $5(9.1)$ & $4(13.3)$ & $1(4.0)$ & \\
\hline Status epilepticus & $13(23.6)$ & $3(10.0)$ & $10(40.0)$ & $0.04 / * \star x$ \\
\hline Prolonged post-ictal period & $7(12.7)$ & $4(13.3)$ & $3(12.0)$ & 0.883 \\
\hline \multicolumn{5}{|l|}{ EEG background activity } \\
\hline Normal & $23(41.8)$ & $12(40.0)$ & $11(44.0)$ & \\
\hline Intermittent slow activity & $13(23.6)$ & $11(36.7)$ & $2(8.0)$ & 0.027 \\
\hline Continuous slow activity & $19(34.5)$ & 7 (23.3) & $12(48.0)$ & \\
\hline EEG epileptiform activity & $38(69.1)$ & $22(73.3)$ & $16(64.0)$ & 0.456 \\
\hline \multicolumn{5}{|l|}{ Epileptic syndromes } \\
\hline Generalized idiopathic & $1(1.8)$ & 1 (3.33) & $0(0.0)$ & \\
\hline Probably symptomatic & $17(30.9)$ & $12(40.0)$ & $5(20.0)$ & 0.175 \\
\hline Symptomatic & $37(67.2)$ & $18(60.0)$ & $19(76.0)$ & \\
\hline Etiology of vascular diseases & $28(50.1)$ & $14(46.7)$ & $14(56.0)$ & 0.425 \\
\hline Number of seizures below 10 & $34(61.8)$ & $16(53.3)$ & $18(72.0)$ & 0.323 \\
\hline Monotherapy with antiepileptic drug & $46(83.6)$ & $22(73.3)$ & $23(92.0)$ & $0.033 * *$ \\
\hline Epilepsy controlled & $43(78.1)$ & 25 (83.3) & $18(72.0)$ & 0.310 \\
\hline
\end{tabular}

EEG: electroencephalogram. *Fisher's exact or $\chi^{2}$ tests; ${ }^{* *} p<0.05$. 


\section{Status epilepticus or seizures in series and the epileptic syndrome}

As can be seen in Table 2, status epilepticus or seizures in series occurred with greater frequency in patients with symptomatic focal epilepsy (56.8\%) than in those with probably symptomatic focal epilepsy $(11.8 \%)\left(\chi^{2}, \mathrm{p}=0.023\right)$.

\section{Number, treatment and control of the ES}

Table 1 shows the data referring to the treatment and control of the ES.

There were less than 10 ES in $34(61.8 \%)$ cases and the epilepsy was under control in $43(78.1 \%)$ cases. An association between a number of ES greater than 10, the finding of EA and continuous or intermittent abnormality of the background activity, was found (Table 3).

Monotherapy with AED was used in 46 (83.6\%) patients, and in a greater proportion in the G60+ group than in the G51-60 group (Fisher's exact test, $\mathrm{p}<0.05$ ).

\section{DISCUSSION}

\section{Epileptic seizures}

In the present study with patients showing an ES onset age over 50 , focal seizures were shown to predominate $(67 \%$ of the patients), in agreement with other studies, which initially found focal seizures in about $70 \%$ of the cases ${ }^{1,8}$.

It was shown that focal seizures, including the complex ones, occurred in a smaller proportion in patients with an ES onset age over 60 than in those with an onset age between 51 and 60 . There were possibly different seizure genesis mechanisms occurring in the older group, but a greater difficulty in obtaining adequate descriptions of the seizures could also have been a factor in this age range.

Complex seizures have been referred to as being more common in the elderly and appear as fluctuations in responsiveness, associated with automatisms. Such episodes can be difficult to characterize, leading to confusion with dementias, memory lapses and even with episodes of mental confusion ${ }^{9}$. Thus, the diagnosis of ES may be retarded or may even not be made, as occurs in about $30 \%$ of the cases ${ }^{3,69-11}$.

Some authors have suggested that complex ES in the elderly present a ictalsemiology distinct from that found in the young adult, since in the elderly the localization most frequently found involves the frontal and parietal lobes and not the temporal lobe ${ }^{4,12}$.

As in the literature, an elevated frequency of status epilepticus and of ES in series was found in the present series. More than $30 \%$ of the ES in the elderly appeared as status epilepticus or seizures in series, the occurrence being twice that found in other age ranges ${ }^{2,13-15}$.

Status epilepticus de novo frequently occurs in the elderly with no prior history of ES and epilepsy, and represents a considerable risk for the subsequent development of epilepsy, as also a worse cognitive prognosis and increase in mortality of up to $40 \%{ }^{16}$.

In this series, status epilepticus was found to a greater extent in those patients with an onset of epilepsy at over 60 , whereas seizures in series occurred predominantly in those with an onset between 51 and 60 years of age. It is possible that this finding is connected to differences in the characteristics of inhibition of the epileptogenic mechanisms connected to age. No similar report was found in the literature.

This research showed that SE and seizures in series occurred more frequently in symptomatic epilepsy than in probably symptomatic epilepsy.

In the elderly, prolonged acute confusional state with a pleomorphic clinical presentation and no associated motor manifestation can be ictal manifestations of non-convulsive SE, and wrongly diagnosed as vascular and psychiatric disorders or even as symptomatic of dementia ${ }^{3,12,17,18}$.

Another relevant clinical aspect of the present series was the report of a prolonged post-ictal period in $13 \%$ of the

Table 2. Epileptic syndromes and status epilepticus or epileptic seizures in series.

\begin{tabular}{lccc}
\multirow{2}{*}{ Status epilepticus or seizures in series } & \multicolumn{2}{c}{ Epileptic syndrome* } & \multirow{2}{*}{ Total } \\
\cline { 2 - 3 } & Symptomatic & Probably symptomatic & 18 \\
Present & $16(43.2)$ & $15(88.2)$ & 36 \\
Absent & $21(56.8)$ & 17 & 54 \\
\hline
\end{tabular}

${ }^{*} \chi^{2}, p=0.023$

Table 3. Number of epileptic seizures and electroencephalogram data.

\begin{tabular}{lcc} 
& \multicolumn{1}{c}{ Number of epileptic seizures } \\
Electroenceplalogram data & $\begin{array}{c}\text { Up to } 10 \\
n=34\end{array}$ & $\begin{array}{c}\text { More than } 10 \\
n=21\end{array}$ \\
\cline { 2 - 3 } & & $3(14.3)$ \\
Epileptiform activity & $14(47.5)$ & $18(85.7)$ \\
Absent & $20(58.8)$ & $5(23.8)$ \\
Present & & $16(76.2)$ \\
Intermittent or continuous slow activity & $18(52.9)$ & $0.036^{*}$ \\
Absent & $16(47.1)$ & $0.033^{*}$ \\
\hline
\end{tabular}

${ }^{*} \chi^{2}, p<0.05$ 
cases, characterized by mental confusion, focal motor deficit, aphasia or psychiatric disorder. Reports can be found in the literature of a post-ictal phase lasting for up to 24 hours in approximately $14 \%$ of patients, the majority of which characterized by confusional states ${ }^{9,19}$ or as Todd's paralysis ${ }^{10,11,19}$.

A prolonged post-ictal period makes the diagnosis of ES difficult and increases the negative impact on the quality of life of the patients ${ }^{2,16}$.

\section{Diagnostic evaluation}

The initial diagnostic evaluation in the older individual with ES should be similar to that applied in younger individuals, and include an EEG and neuroimaging exam in addition to the general examinations.

Although there are few studies with EEG for the first ES in older individuals ${ }^{20-22}$, there is evidence that the EEG should be routinely applied as an important part in the diagnosis and prognosis with respect to the risk of a recurrence of the ES ${ }^{21}$.

However it is known that a single EEG can produce a false negative result and a normal or non-specific exam should not include a diagnosis of epilepsy ${ }^{8,20}$.

Alterations in thebackground activity or non-specific symptoms can appear on the EEG of elderly individuals with advancing age, and EA can become less frequently associated with $\mathrm{ES}^{4}$. Some studies report the presence of epileptiform activity in 20 to $37 \%$ of epileptic patients over 60 years of age $e^{2,6,20,22}$.

In the present research, the finding of EA in about $70 \%$ of the cases may have been due to recording the EEG soon after the ES. An association was found between a greater number of seizures (more than 10), the presence of EA and the continuous or intermittent abnormality of thebackground activity, but such a correlation has not been evaluated and described in the literature.

The electroencephalographic recording of an ES would be the "golden standard" for the diagnosis of an epileptic seizure $^{19,22}$, and in two of the patients in the present study recordings of focal ES were obtained.

As in the EEG recordings, age-related changes are frequently seen on the MRI and include diffuse atrophy, dilatation of the Virchow-Robin perivascular spaces and periventricular hyperintensity, and one should be careful not to attribute the cause of epilepsy to such non-specific findings ${ }^{19,22}$.

Intracranial calcifications were found in seven cases in the neuroimaging exams carried out in the present study, and basal ganglia calcifications in one case, but without any causal relationship with the ES. The elevated proportion of intracranial calcifications in our medium due to neurocysticercosis is well known, with no associated neurological manifestation ${ }^{23}$. On the other hand, the finding of basal ganglia calcifications, suggestive of Fahr's disease, as observed in one patient diagnosed with symptomatic epilepsy with vascular etiology, can be considered incidental ${ }^{23}$.
Thus the overall clinical picture should be considered judiciously in the valorization of the results of an imaging exam ${ }^{19,22}$.

\section{Epileptic syndromes}

Symptomatic epilepsy

In the present study, in agreement with the literature, practically two thirds of the cases were diagnosed as symptomatic epilepsy, and the etiology identified with greater frequency was cerebrovascular disease in approximately $55 \%$ of the cases

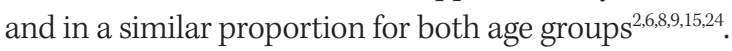

The following etiologies were also found, equally in agreement with the literature: traumatic brain injury, intracranial arteriovenous malformation and degenerative disease ${ }^{6,8,24}$.

The etiology was neurocysticercosis in two cases, with viable cysts visible in the neuroimaging exam. No articles were found in the literature with the vesicular form of neurocysticercosis as the etiology for epilepsy in the aged. In one case ES of the GTC type occurred immediately following the installation of an ischemic stroke. However, the autonomic/complex ES that appeared subsequently was suggestive of temporal lobe epilepsy, and must be related to the temporal mesial sclerosis found on the MRI of the patient. It is disputable whether the temporal mesial sclerosis occurred after the stroke or not, since no MRI was carried out beforehand.

\section{Probably symptomatic focal epilepsy}

In about one third of the cases the etiology was not determined, similar to the report of probably symptomatic epilepsy in $25-45 \%$ of new cases of epilepsy in the aged ${ }^{15,16,25}$.

ES and epilepsy can be the first sign of a still not manifested vascular disease. It is believed that the risk of epilepsy is greater in hypertensive individuals, probably because of small vessels lesions that lead to "irritative symptoms" before causing an ictus ${ }^{25-27}$. Late-onset ES would thus be a predictive factor for a subsequent stroke ${ }^{27}$.

\section{Idiopathic generalized epilepsy}

Idiopathic generalizes epilepsy (IGE) with its onset as an adult, as observed in one case in this series, is very rare, but it is a possibility that should not be rejected in the diagnosis of IGE in the aged ${ }^{28,29}$.

Late-onset IGE at over 50, resulting of a known or presumed genetic defect, is considered to be rare. Twenty-four individual cases have been reported in the literature ${ }^{28,29}$. Recognition of late-onset IGE in the elderly has implications for an adequate diagnosis and treatment ${ }^{30}$.

\section{Treatment and control of the epileptic seizures}

Similar to that reported in the literature, an adequate control of the ES was found with the use of a single AED ${ }^{16,30}$, the percentage of patients in monotherapy being higher in the G60+ group than in the G51-60 group. 
Although there is no consensus with respect to the treatment ${ }^{19,22}$, some studies suggest the introduction of AED after the first ES and for an indeterminate period due to the risk of recurrence of the ES, which occurs in $90 \%$ of the cases after suspension of the medication ${ }^{2,825}$.
In conclusion, epilepsy in the elderly is a common condition representing approximately $25 \%$ of new cases of epilepsy in the population, and shows peculiarities in the clinical expression, diagnosis, clinical - laboratory correlations, prognosis, therapy and quality of life, which justify new research lines.

\section{References}

1. Hauser WA, Annegers JH, Kurland LT. Prevalence of epilepsy in Rochester, Minnesota: 1940-1980. Epilepsia 1991;32:429-445.

2. Stephen LJ, Brodie MJ. Management of a first seizure. Special problems adults and elderly. Epilepsia 2008;49:45-49.

3. Brodie MJ, Elder T, Kwan P. Epilepsy in later life. Lancet Neurol 2009;8:1019-1030.

4. Ramsay RE, Pryor FM. Epilepsy in the elderly. Neurology 2000;55(5 Suppl 1):S9-S14.

5. Rowan AJ, Epiplepsy Foundation of America. Epilepsy in older adults. Common morbidities influence development, treatment strategies, and expected outcomes. Geriatrics 2005;60:30-34.

6. Massengo SA, Ondze B, Guiziou C, Velmans N, Rajabally YA. Elderly patients with epileptic seizures: in-patient observational study of two French community hospitals. Seizure 2011;20:231-239.

7. Engel Jr J, International League Against Epilepsy (ILAE). A proposed diagnostic scheme for people with epileptic seizures and with epilepsy: report of the ILAE task force on classification and terminology. Epilepsia 2001;42:796-803

8. Tebartz van Elst L, Baker G, Kerr M. The psychosocial impact of epilepsy in older people. Epilepsy Behav 2009;15(Suppl 1):S17-S19.

9. Ramsay RE, Rowan AJ, Pryor FM. Special considerations in treating the elderly patient with epilepsy. Neurology 2004;62 (5 Suppl 2):S24-S29.

10. Hommet C, Mondon K, Camus V, De Toffol B, Constans T. Epilepsy and dementia in the elderly. Dement Geriatr Cogn Disord 2008;25:293-300.

11. Hopkins AF, Garman A F, Clark C. The first seizure in adult life. Value of clinical features, electroencephalograpy, and computerized tomographic scanning in prediction of seizure recurrence. Lancet 1988;1:721-726.

12. Belmin J, Marquet T, Oasi C. [Anti-epileptic drugs and their use in the elderly]. Presse Med 2000; 2:2143-2148.

13. Shorvon SD. Epidemiology, classification, nature history, and genetics of epilepsy. Lancet 1990;336:93-96.

14. Wright JF, Pickard NF, Witfield AF. A population-based study of the prevalence, clinical characteristics and effect of ethnicity epilepsy. Seizure 2000;9:309-313

15. Hauser WA, Annegers JH, Kurland LT. Prevalence of epilepsy in Rochester, Minnesota: 1940-1980. Epilepsia 1991;32:429-445.
16. Cloyd J, HauserW, Ramsay R, et al. Epidemiological and medical aspects of epilepsy in the elderly. Epilepsy Res 2006;68(Suppl 1):S39-S48.

17. Pollock LM, Mitchell SC. Nonconvulsive status epilepticus causing acute confusion. Age Ageing 2000;29:360-362.

18. Veran O, Kahane P, Thomas P, Hamelin S, Sabourdy C, Vercueil L. De novo epileptic confusion in the elderly: a 1-year prospective study. Epilepsia 2010;51:1030-1035.

19. Kellinghaus C, Loddenkemper T, Dinner DS, Lachwani D, Lüders H. Seizure semiology in the elderly: a video analysis. Epilepsia 2004; $45: 263-267$

20. Van Cott AC. Epilepsy and EEG in the elderly. Epilepsia 2002;43(Suppl 3):94-102.

21. Krumholz A, Wiebem S, Gronsethm G, et al. Practice parameter: evaluating an apparent unprovoked first seizure in adults (an evidencebased review): report of the Quality Standards Subcommittee of the American Academy of Neurology and the American Epilepsy Society. Neurology 2007;69:1996-2007.

22. Sinha S, Satishchandra P, Kalband BR, Thennarasu K. EEG observations in elderly with new onset seizures: from developing country perspective. J Clin Neuropsysiol 2011;28:388-393.

23. Tedrus GMAS, Fonseca LC, Nogueira Jr E. Calcificação nos núcleos da base na tomografia computadorizada: correlação clínica em 25 pacientes consecutivos. Arq Neuropsiquiatr 2006;64:104-107.

24. Roberson ED, Hope OA, Martin RC, Schmidt D. Geriatric epilepsy: research and clinical directions for the future. Epilepsy Behav 2011;22:103-111.

25. Poza JJ. Management of epilepsy in the elderly. Neuropsychiatric Dis Treat 2007;3:723-728.

26. Ng SKC, Hauser WA, Brust JCM, Susser M. Hypertension and the risk of new-onset unprovoked seizures. Neurology 1993;43:425-428.

27. Cleary P, Shorvon S, Tallis R. Late-onset seizures as a predictor of subsequent stroke. Lancet 2004;363:1184-1186.

28. Hiyohi T, Yagi K. Epilepsy in the elderly. Epilepsia 2000;41(Suppl 9):31-35

29. Michel VHN, Sebban C, Debray-Meignan S, et al. Electroclinical features of idiopathic generalized epilepsies $n$ the elderly: a geriatric hospital-based study. Seizure 2011;20:292-298.

30. Bagshaw J, Crawford P, Chappell B. Care in people 60 years of age and over with chronic or recently diagnosed epilepsy: a note review in United Kingdom general practice. Seizure 2009;18:57-60. 